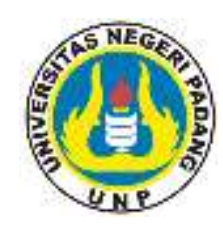

\title{
ANALISIS JENIS DAN STRUKTUR KALIMAT DALAM SAKUBUN MAHASISWA SEMESTER IV PRODI PENDIDIKAN BAHASA JEPANG UNIVERSITAS NEGER PADANG
}

\author{
Ani Hardianti ${ }^{1}$, Hendri Zalman ${ }^{2}$ \\ Prodi Pendidikan Bahasa Jepang, Fakultas Bahasa dan Seni, Universitas Negeri Padang \\ Prodi Pendidikan Bahasa Jepang, Fakultas Bahasa dan Seni, Universitas Negeri Padang \\ Email Penulis : anihardianti25@gmail.com
}

\begin{tabular}{ll}
\hline Sejarah Artikel \\
\hline Submit $\quad: 2019-07-26$ \\
Diterima $: 2019-08-19$ \\
Diterbitkan $:$ 2019-08-30
\end{tabular}

\begin{abstract}
Abstrak
This study is aimed to: describe the type and structure of sentences in the fourth semester students of the UNP Japanese language education study program. This research is a qualitative research with descriptive method The data used in this study are sentences based on the type and structure obtained from the student. Sources of data taken are sakubun fourth semester students of UNP Japanese.

language education study program totaling 30 sakubun. The results of this study are as follows; First, the types of sentences based on the predicate that is used in the fourth semester students of UNP Japanese language study program, researcher found 255 sentences. 195 doushibun sentences consisting of 135 types of tadoushibun sentences, 60 types of jidoushibun sentences. 29 Keiyoushibun sentences consisting of 7 types of sentences i-keiyoushi, 22 types of sentences nakeiyoushi, and Meishibun sentence types are 31. Second, the sentence of the structure that is used in the fourth semester students of UNP Japanese language study program, the researcher found 255 sentences. 49 sentences with SP structure, 72 sentences with SOP structure, 1 sentences with SOKP structure, and 133 other structured sentences
\end{abstract}

\section{Kata Kunci:}

Type of sentence based on predicate, sentence structure

\section{PENDAHULUAN}

Menulis merupakan salah satu keterampilan berbahasa yang penting untuk dikuasai oleh pembelajar bahasa asing, termasuk pembelajar bahasa Jepang. Sutedi (2009:2) mengatakan bahwa keterampilan menulis dalam bahasa Jepang dapat digolongkan ke dalam tiga macam, yaitu: menulis huruf (Kana dan Kanji), menulis kalimat (Bunsaku), menulis cerita/karangan (Sakubun). Zalman (2012:2) mengatakan bahwa pembelajaran menulis biasanya diaplikasikan pada mata kuliah hyouki (huruf hiragana dan katakana), kanji (huruf kanji), bunpo (tata bahasa), dan mata kuliah sakubun. Mata kuliah hyouki outputnya adalah hafalan huruf hiragana dan katakana. 
Mata kuliah kanji adalah hafalan huruf kanji, bunpou adalah hafalan aturan bentuk, penggunaan kata dan pola kalimat. Sedangkan mata kuliah sakubun merupakan aplikasi dari ketiga mata kuliah sebelumnya. Outputnya adalah berupa kalimat, paragraf, laporan, karangan, dan lain sebagainya

Dalam (Sudjianto, 2010:3) mengatakan bahwa sakubun merupakan sebuah pengajaran yang diberikan untuk memberikan keterampilan dalam menulis karangankarangan tertentu, dari menulis kalimat yang sangat sederhana sampai pada yang lebih kompleks. Menurut Alwasilah (dalam Sutedi, 2009:2) kemampuan sakubun ditunjang oleh dua kemampuan pokok, yaitu kemampuan linguistik dan kemampuan komposisi. Kemampuan linguistik adalah kemampuan dalam menguasai bahasa Jepang, mulai dari penguasaan huruf (kana dan kanji), kosakata, pola kalimat, ungkapan, dan aturan gramatika yang berlaku dalam bahasa Jepang. Adapun yang dimaksud dengan kemampuan komposisi adalah kemampuan menyajikan cerita atau isi karangan berdasarkan alur tertentu yang sesuai dengan budaya dan kebiasaan penutur bahasa Jepang.

Berdasarkan keterangan di atas, bisa diasumsikan bahwa komposisi sakubun terdiri dari dua aspek yaitu aspek teknis dan aspek kebahasaan. Aspek teknis yaitu berupa isi dan strukur teks, sedangkan aspek kebahasaan berupa bunpou dan mojigoi. Jadi, sakubun sebenarnya adalah sarana untuk mengaplikasikan sekaligus mengkreasikan aspek kebahasaan, terutama penggunaan kata dan kalimat yang dipelajari.

Kalimat dalam bahasa Jepang terdiri dari berbagai macam jenis kalimat. Menurut Sutedi (2003:67-69), ditinjau dari segi predikat, jenis kalimat bahasa Jepang terdiri dari; doushibun (kalimat verbal), keiyoushibun (kalimat adjectival), meishibun (kalimat nominal). Ditinjau dari aspek jumlah klausanya, kalimat bahasa Jepang terdiri dari; tanbun (kalimat tunggal), fukubun (kalimat majemuk). Sedangkan, jika ditinjau dari fungsinya, kalimat bahasa Jepang terdiri dari; joutaibun (kalimat menyatakan keadaan), ugoki no bun (kalimat menyatakan aktifitas), hataraki-kake no bun (kalimat perintah/permohonan), ishi/ ganbou no hyoushutshubun (kalimat menyatakan maksud), nobetate no bun (kalimat berita), dan toikake no bun (kalimat tanya), dan lain sebagainya. Banyaknya jenis kalimat daalam bahasa Jepang tentu menjadi kesulitan tersendiri bagi pembelajaran bahasa Jepang, terutama pembelajar bahasa Jepang penutur asing, seperti penutur Indonesia.

Di samping jenis kalimat di atas, kalimat bahasa Jepang juga memiliki karakteristik khas jika ditinjau dari segi pola/strukturnya. Sutedi (2003 : 229) menyatakan bahwa struktur kalimat dalam bahasa Jepang terdiri dari; SubjekPrediket (S-P), Subjek-Objek-Prediket (S-O-P), dan Subjek-Objek-KeteranganPrediket (S-O$\mathrm{K}-\mathrm{P})$. Struktur ini jelas berbeda dengan struktur bahasa

Mahasiswa Prodi Pendidikan Bahasa Jepang FBS UNP lulus pada tanggal......

${ }^{2}$ Dosen Prodi Pendidikan Bahasa Jepang FBS UNP 
Indonesia, yaitu; S-P, S-P-O, dan S-P-O-K. Sama seperti persoalan jenis kalimat di atas, maka persoalan struktur ini tentu juga menjadi kendala/kesulitan bagi pembelajar bahasa Jepang penutur Indonesia dalam berbahasa Jepang, seperti berbicara dan menulis kalimat hingga sakubun

Di dalam proses pembelajaran sakubun, salah satu masalah yang dihadapi pengajar adalah terkait dengan kalimat yang dihasilkan oleh mahasiswa. Zalman (2012) dalam penelitiannya tentang "Pengembangan Teknik $5 \mathrm{~W}+1 \mathrm{H}$ dalam Pembelajaran Sakubun: Studi Eksperimental terhadap Mahasiswa Tahun Masuk 2008 UNNES" mengatakan bahwa kalimat yang muncul tidak bervariasi dan cenderung sama dengan yang ada di buku teks. Di samping itu, Sutedi (2008) juga mengemukan bahwa di dalam pembelajaran menulis sakubun, ada kelompok mahasiswa yang bisa menulis kalimat dengan baik, tapi tidak mampu melakukannya dalam menulis sakubun. Bahkan, mahasiswa banyak menghabiskan waktu pada kegiatan awal menulis memikirkan tentang struktur kalimat yang akan mereka gunakan dalam sakubun tersebut.

\section{METODE PENELITIAN}

Metode penelitian yang digunakan dalam penelitian ini adalah deskriptif kulitatif, yaitu metode penelitian yang menghasilkan data deskriptif berupa katakata tertulis atau lisan dari orang-orang atau perilaku yang diamati (Bogdan dalam Moleong, 2002:3). Data dari penelitian ini adalah kalimat berdasarkan jenis dan strukturnya yang di peroleh dari sakubun mahasiswa. Sedangkan sumber data dalam penelitian ini adalah sakubun mahasiswa semester IV prodi pendidikan bahasa Jepang Universitas Negeri Padang. Jumlah sakubun yang diteliti adalah 30, yang berasal dari 30 mahasiswa prodi pendidikan bahasa Jepang Universitas Negeri Padang.

Instrumen penelitian adalah suatu alat atau fasilitas yang digunakan peneliti dalam mengumpulkan data. Menurut Sugiyono (2014:222) dalam penelitian kualitatif, yang menjadi instrumen penelitian atau alat penelitian adalah peneliti itu sendiri. Instrumen utama dalam penelitian ini adalah peneliti sendiri. Peneliti secara langsung membaca, memahami, mengidentifikasikan, dan mencatat hal-hal yang berkaitan dengan jenis dan struktur kalimat dalam sakubun mahasiswa semester IV prodi pendidikan bahasa Jepang Universitas Negeri Padang. Peneliti dibantu dengan alat penelitian berupa format inventarisasi untuk mencatat dan menganalisis data.

Adapun teknik pengumpulan data sebagai berikut. Pertama, membaca saakubun mahasiswa. Kedua, mengambil data berupa kalimat berdasarkan jenis dan struktur kalimat. Ketiga, mengumpulkan data ke dalam tabel inventarisasi data. Kemudian dilanjutkan dengan menganalisis data dengan langkah sebagai berikut. Pertama, peneliti menggunakan teknik bagi unsur langsung, peneliti membagi satuan lingual data dan satuan paragraf untuk menganalisis jenis dan struktur kalimat. Kedua, mengklasifikasikan data jenis kalimat berdasarakan predikat dengan menggunakan 
tabel. Ketiga, mengklasifikasikan data berdasarkan struktur kalimat dengan menggunakan tabel. Keempat, setelah dianalisis, peneliti menggunakan teknik trianggulasi untuk mengkonsultasikan hasil analisis data kepada ahli. kelima, setelah mendappatkan data yang valid, peneliti menggunakan teknik analisis deskriptif untuk menjelaskan hasil analisis data secara rinci dan jelas. Terakhir, kesimpulan.

\section{HASIL DAN PEMBAHASAN}

\section{Temuan penelitian}

Berdasarkan data yang telah dikumpulkan, maka didapatkan jumlah jenis kalimat berdasarkan predikat dan struktur kalimat dalam sakubun mahasiswa semester IV prodi pendidikan bahasa Jepang Universitas Negeri Padang sebagai berikut. a. Jenis kalimat berdasarkan predikat dalam sakubun mahasiswa semester IV prodi pendidikan bahasa Jepang UNP.

a. Jenis kalimat berdasarkan predikat dalam sakubun mahasiswa semester IV prodi pendidikan bahasa Jepang UNP.

Berikut jumlah jenis kalimat berdasarkan predikat dalam sakubun mahasiswasemester IV prodi pendidikan bahasa Jepang UNP :

Tabel 1.

Jumlah Jenis Kalimat Berdasarkan Predikat

\begin{tabular}{|l|l|l|l|}
\hline No & Jenis Kalimat Berdasarkan Prediket & Frekuensi \\
\hline 1 & \multirow{2}{*}{ Doushibun } & Tadoushibun & 135 \\
\cline { 3 - 4 } & & Jidoushibun & 60 \\
\hline 2 & \multirow{2}{*}{ Keiyoushibun } & I-keiyoushi & 7 \\
\cline { 3 - 4 } & & Na-keiyoushi & 22 \\
\hline 3 & Meishibun & 31 \\
\hline & Total & 255 \\
\hline
\end{tabular}

Berdasarkan tabel di atas dapat diketahui bahwa, pada penelitian ini ditemukan 255 kalimat. Jenis kalimat doushibun sebanyak 195 yang terdiri dari 135 jenis kalimat tadoushibun, 60 jenis kalimat jidoushibun. Jenis kalimat Keiyoushibun sebanyak 29 yang terdiri dari 7 jenis kalimat i-keiyoushi, 22 jenis kalimat nakeiyoushi. Jenis kalimat meishibun berjumlah 31. Dari data tersebut dapat disimpulkan bahwa mahasiswa semester IV prodi pendidikan bahasa Jepang UNP lebih banyak menghasilkan kalimat dengan jenis doushibun dibandingkan jenis kalimat lainnya 
b. Struktur kalimat dalam sakubun mahasiswa semester IV prodi pendidikan bahasa Jepang UNP lain-lain.

Berikut jumlah jenis kalimat berdasarkan predikat dalam sakubun mahasiswa semester IV prodi pendidikan bahasa Jepang UNP :

Tabel 2.

Jumlah Struktur Kalimat

\begin{tabular}{|c|l|c|}
\hline NO & Struktur Kalimat & Frekuensi \\
\hline $\mathbf{1}$ & SP & 49 \\
\hline $\mathbf{2}$ & SOP & 72 \\
\hline $\mathbf{3}$ & SOKP & 1 \\
\hline $\mathbf{4}$ & Struktur Lain & 133 \\
\hline & \multicolumn{2}{|c|}{ Total } \\
\hline
\end{tabular}

Berdasarkan tabel di atas dapat diketahui bahwa, pada penelitian ini ditemukan 255 kalimat. Dapat diketahui bahwa kalimat yang berstruktur SP sebanyak 49, kalimat yang berstruktur SOP berjumlah 72, kalimat yang berstruktur SOKP sebanyak 1, dan kalimat yang berstruktur lain yaitu 133. Dari data tersebut dapat disimpulkan bahwa mahasiswa semester IV prodi pendidikan bahasa Jepang UNP lebih banyak menghasilkan kalimat dengan struktur kalimat dan lain-lain. dibandingkan struktur kalimar SP, SOP, dan SOKP

\section{Pembahasan}

Berdasarkan temuan penelitian di atas, maka berikut disajikan hasil analisis data : a. Jenis kalimat berdasarkan predikat dalam sakubun mahasiswa semester IV prodi pendidikan bahasa Jepang UNP.

Berdasarkan hasil analisis data pada penelitian ini ditemukan 255 kalimat. Jenis kalimat doushibun sebanyak 195 yang terdiri dari 135 jenis kalimat tadoushibun, 60 jenis kalimat jidoushibun. Jenis kalimat keiyoushibun sebanyak 29 yang terdiri dari 7 jenis kalimat i-keiyoushibun, 22 jenis kalimat nakeiyoushibun. Jenis kalimat meishibun berjumlah 31. Dari data tersebut dapat disimpulkan bahwa mahasiswa semester IV prodi pendidikan bahasa Jepang UNP lebih banyak menghasilkan kalimat dengan jenis doushibun khususnya jenis kalimat tadoushibun. Berikut pembahasan data jenis kalimat berdasarkan predikat dalam sakubun mahasiswa semester IV prodi pendidikan bahasa Jepang UNP.

1). Doushibun 
Doushibun yaitu kalimat yang berpredikat verbal. Peneliti menemukan 195 kalimat yang berpredikat doushibun, dimana dari 195 kalimat doushibun terdiri dari 135 kalimat tadoushibun dan 60 kalimat jidoushibun. Berikut uraian contoh data kalimat tadoushibun dan jidoushibun dalam sakubun mahasiswa semester IV prodi pendidikan bahasa Jepang UNP. a) Tadoushibun (kalimat transitif) Tadoushibun yaitu kalimat yang perdikatnya memerlukan atau dapat diberi objek dan biasanya diikuti dengan partikel ‘o’ (を). Peneliti menemukan 135 kalimat yang berpredikat tadoushibun (kalimat transitif).

Contoh :

[1] 今一番大切なことは日本語をべんきょうします。

Ima ichiban taisetsuna koto wa nihongo o benkyoushimashu.

Sekarang hal yang terpenting adalah belajar bahasa Jepang. (SP1.K03)

Berdasarkan jenis kata yang menjadi predikatnya data [1] di atas termasuk dalam kalimat tadoushibun (kalimat transitif). Pada data [1] kata yang menjadi predikatnya 'benkyoushimasu' (ベんきょうします). Sejalan dengan teori di atas,

bahwa kalimat tadoushibun memerlukan objek, dimana objek ditandai dengan partikel „,oe (を). Pada data [1] yang menjadi objeknya 'nihonggo' (日本語)

b) Jidoushibun (kalimat intransitif)

Jidoushibun yaitu kalimat yang perdikatnya tidak memerlukan objek dan biasanya diikuti dengan partikel 'ga' (が). Peneliti menemukan 60 kalimat yang berpredikat jidoushibun (kalimat intransitif).

Contoh :

[2] 7 年後にほんへいきます。

7 nen ato nihon e ikimasu.

Setelah 7 tahun saya akan pergi ke Jepang.

(SP1.K05).

Berdasarkan jenis kata yang menjadi predikatnya data [6] di atas termasuk dalam kalimat jidoushibun (kalimat intransitif). Pada data [6] kata yang menjadi predikatnya 'ikimasu’ (いきます). Sejalan dengan teori di atas, bahwa kalimat jidoushibun tidak memerlukan objek. Kata kerja ikimasu menunjukkan perpindahan subjek dari suatu tempat ketempat lain. Dalam data [6] tempat yang menjadi gerak tersebut dinyatakan dengan partikel 'e' $(\sim)$. Partikel 'e' $(\sim)$ biasanya memiliki arti "ke".

\section{2) Keiyoushibun}

Keiyoushibun yaitu kalimat yang berpredikat adjektival. Peneliti menemukan 35 kalimat yang berpredikat keiyoushibun, dimana dari 29 kalimat keiyoushibun terdiri dari 7 kalimat i-keiyoushi dan 22 kalimat na-keiyoushi. Berikut uraian contoh 
data kalimat i-keiyoushi dan na-keiyoushi dalam sakubun mahasiswa semester IV prodi pendidikan bahasa Jepang UNP.

a) I-keiyoushi (kata sifat -I)

keiyoushi yaitu kalimat yang predikatnya menggunakan kata sifat -I. Peneliti menemukan 11 kalimat yang berpredikat i-keiyoushi (kata sifat -i).

Contoh :

[3] 子供がかわいいですから。

Kodomo ga kawaii desukara.

Karena anak kecil lucu.

(SP25.K250)

Predikat data [3] di atas termasuk dalam kalimat i-keiyoushi (kata sifat-i). Pada data [3] kata yang menjadi predikatnya 'kawaii desu kara' (かわいいですから). Kata kawaii termasuk kedalam kata sifat $i$-keiyoushi, sementara kata 'desu kara' (で すから) merupakan kopula atau jodoushi. Fungsi utama kopula yaitu untuk menyatakan suatu predikat dalam data [3]. Selain sebagai kopula kata 'desu kara' (で すから) juga merupakan pola yang menyatakan sebab atau alasan.

b) Na-keiyoushi (kata sifat $-\mathrm{Na}$ )

Na-keiyoushi yaitu kalimat yang predikatnya menggunakan kata sifat -Na. Peneliti menemukan 24 kalimat yang berpredikat na-keiyoushi (kata sifat -na). Contoh :

[4]パイロットはとても親切です。

Pairotto wa totemo shinsetsu desu.

Pilot sangatlah ramah.

(SP6.K45)

Berdasarkan jenis kata yang menjadi predikatnya data [4] di atas termasuk dalam kalimat na-keiyoushi (kata sifat-na). Pada data [4] kata yang menjadi predikatnya 'shinsetsu desu' (親切です). Kata shinsetsu termasuk kedalam kata sifat na-keiyoushi, sementara kata 'desu' (です) merupakan kopula atau jodoushi. Fungsi utama kopula yaitu untuk menyatakan suatu predikat dalam data [4].

3) Meishibun

Jenis kalimat berdasarkan predikat dalam sakubun mahasiswa semester IV prodi pendidikan bahasa Jepang UNP yang ketiga yaitu meishibun. Meishibun yaitu kalimat yang berpredikat nominal atau kata benda.

Contoh :

[5] 今一番大切なことは大学で勉強です。

Ima ichiban taisetsuna kotowa daigaku de benkyou desu.

Sekarang hal yang terpenting adalah belajar di kampus. 
( SP4.K20)

Berdasarkan jenis kata yang menjadi predikatnya data [5] di atas termasuk dalam kalimat meishibun (kata nominal). Pada data [5] kata yang menjadi predikatnya 'benkyou desu’ (勉強です). Kata benkyou termasuk kedalam kata meishi, sementara kata 'desu' (です) merupakan kopula atau jodoushi. Fungsi utama kopula yaitu untuk menyatakan suatu predikat dalam data [5].

Dari uraian di atas dapat disimpulkan bahwa mahasiswa semester IV prodi pendidikan bahasa Jepang UNP lebih banyak menghasilkan kalimat dengan jenis doushibun khususnya jenis kalimat tadoushibun yaitu 135 kalimat. b. Struktur kalimat dalam sakubun mahasiswa semester IV prodi pendidikan bahasa Jepang UNP.

Seperti yang telah dipaparkan pada bagian analisis data, struktur kalimat bahasa Jepang yaitu SP, SOP, dan SOKP. Pada penelitian ini ditemukan kalimat. Dapat diketahui bahwa kalimat yang berstruktur SP berjumlah 49, kalimat yang berstruktur SOP berjumlah 72, kalimat yang berstruktur SOKP sebanyak 1, dan kalimat yang berstruktur lain yaitu 133. Dari data tersebut dapat disimpulkan bahwa dalam sakubun mahasiswa semester IV prodi pendidikan bahasa Jepang UNP lebih banyak menghasilkan kalimat dengan struktur kalimat lain dibandingkan struktur kalimat SP, SOP, dan SOKP. Struktur kalimat lain yaitu berjumlah 201 kalimat. Berit pembahasan data struktur kalimat dalam sakubun mahasiswa semester IV prodi pendidikan bahasa Jepang UNP.

1) $\mathrm{SP}$

Kalimat dengan struktur kalimat SP dalam dalam sakubun mahasiswa semester IV prodi pendidikan bahasa Jepang UNP adalah 49 kalimat. Contoh :

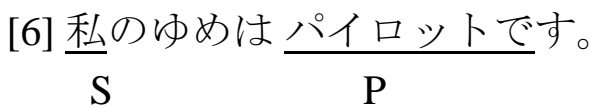

Watashi no yume wa pairotto desu.

Impian saya adalah menjadi pilot.

(SP6.K39)

Data [6] di atas adalah data kalimat yang berstruktur SP dalam sakubun mahasiswa semester IV prodi pendidikan bahasa Jepang UNP. Data [6] bersubjek’watashi' (私) dan berpredikat 'pairotto desu' ( パイロットです). 2) SOP

Kalimat dengan struktur kalimat SOP dalam dalam sakubun mahasiswa semester IV prodi pendidikan bahasa Jepang UNP adalah 77 kalimat.

Contoh :

[7] 私の夢はやくしやになることです。

Watashi no yume wa yakusha ni naru koto desu.

Impian saya adalah menjadi seorang aktor. 
(SP2.K07)

Data [7] adalah data kalimat yang berstruktur SOP dalam sakubun mahasiswa semester IV prodi pendidikan bahasa Jepang UNP. Data [7] bersubjek'watashi' (私), berobjek 'yakusha' (やくしや), dan berpredikat 'naru koto desu' (なることです).

\section{3) SOKP}

Kalimat dengan struktur kalimat SKOP dalam dalam sakubun mahasiswa semester IV prodi pendidikan bahasa Jepang UNP adalah 4 kalimat.

Contoh : [8] 私は子供がとても好きです。

$$
\mathrm{S} \quad \mathrm{O} \quad \mathrm{K} \quad \mathrm{P}
$$

Watashi wa kodomo ga totemo suki desu.

Saya sangat menyukai anak-anak.

(SP25.K190)

Data [8] adalah kalimat yang berstruktur SOKP dalam sakubun mahasiswa semester IV prodi pendidikan bahasa Jepang UNP. Datat [8] bersubjek 'watashi' ( 私 ), berobjek 'kodomo' ( 子 供 ), berketerangan 'totemo' ( とても ), dan berpredikat 'suki desu’ (好きです). Data [8] fungtor pengisi predikat yaitu berupa adjektiva. 4) Struktur Kalimat Lain Kalimat dengan struktur kalimat lain dalam dalam sakubun mahasiswa semester IV prodi pendidikan bahasa Jepang UNP adalah 201 kalimat. Struktur kalimat lain maksudnya adalah kalimat yang tidak menggunakan struktur kalimat bahasa Jepang secara umum (SP, SOP, SOKP). Contoh :

[9]私の夢は日本でインドネシア語のきょうしになりたいです。

$$
\mathrm{S} \quad \mathrm{K} \quad \mathrm{O} \quad \mathrm{P}
$$

Watashi no yume wa nihon de indoneshia no kyoushi ni naritai desu. Impian saya adalah ingin menjadi guru bahasa Indonesia di Jepang.

(SP1.K01) Kalimat [9] adalah data kalimat yang berstruktur lain yang ditemukan dalam sakubun mahasiswa semester IV prodi pendidikan bahasa Jepang UNP. Kalimat [10] berstruktur SKOP yaitu bersubjek'watashi' ( 私 ), berketerangan'nihon' (日本), berobjek 'kyoushi' (きょうし), dan berpredikat 'naritai desu' (なりたいです). Dari paparan di atas dapat disimpulkan bahwa struktur kalimat yang banyak digunakan dalam sakubun mahasiswa semester IV prodi pendidikan bahasa Jepang UNP adalah struktur kalimat lain atau selain struktur kalimat bahasa Jepang pada umumnya (SP, SOP, dan SOKP) yaitu berjumlah 133 kalimat. Hal ini terjadi karena dalam menulis sakubun atau karangan bahasa Jepang struktur kalimat tidak begitu diperhatikan, karena hal terpenting dalam menulis sakubun adalah memahami penggunaan pola kalimat, memahami penggunaan 
partikel, menguasai kosakata bahaa Jepang dan memahami penggunaan kata kerja dan perubahannya. Kemudian karena struktur kalimat bahasa Indonesia dengan bahasa Jepang sangat berbeda sehingga menyebabkan banyak orang merasa sulit dalam membentuk kalimat bahasa Jepang terutama pelajar asing yang baru belajar ISSN 2613-9022 Omiyage Vol 2 No 322 ONLINE ISSN 2613 - 9022 UNP JOURNALS bahasa Jepang. Seperti yang kita ketahui bahwa struktur kalimat bahasa Indonesia SPOK sedangkan struktur kalimat bahasa Jepang SOKP. Meskipun struktur kalimat dalam sakubun tidak terlalu diperhatikan namun struktur kalimat bahasa Jepang wajib diketahui dan dipelajari terutama dalam Sub disiiplin sintaksis bahasa Jepang

\section{KESIMPULAN}

Berdasarkan hasil analisis data penelitian yang telah dilakukan, dapat disimpulkan hal berikut

1. Jenis kalimat berdasarkan predikat yang digunakan dalam sakubun mahasiswa semester IV prodi pendidikan bahasa Jepang UNP peneliti menemukan 255 kalimat. Jenis kalimat doushibun sebanyak 195 yang terdiri dari 135 jenis kalimat tadoushibun, 60 jenis kalimat jidoushibun. Jenis kalimat Keiyoushibun sebanyak 29 yang terdiri dari 7 jenis kalimat ikeiyoushi, 22 jenis kalimat na-keiyoushi. Jenis kalimat meishibun berjumlah 31. Mahasiswa semester IV prodi pendidikan bahasa Jepang UNP lebih banyak menghasilkan kalimat dengan jenis kalimat doushibun dibandingkan jenis kalimat lainnya.

2. Struktur kalimat yang digunakan dalam sakubun mahasiswa semester IV prodi pendidikan bahasa Jepang UNP peneliti menemukan 255 kalimat. Kalimat yang berstruktur SP sebanyak 49, kalimat yang berstruktur SOP berjumlah 72, kalimat yang berstruktur SOKP sebanyak 1, dan kalimat yang berstruktur lain sebanyak 133 . Dari data tersebut dapat diketahui bahwa mahasiswa semester IV prodi pendidikan bahasa Jepang UNP lebih banyak menghasilkan kalimat dengan struktur kalimat lain dibandingkan struktur kalimat SP, SOP, dan SOKP. Hal ini terjadi karena dalam menulis sakubun atau karangan bahasa Jepang struktur kalimat tidak begitu diperhatikan, karena hal terpenting dalam menulis sakubun adalah memahami penggunaan pola kalimat, memahami penggunaan partikel, menguasai kosakata bahaa Jepang dan memahami penggunaan kata kerja dan perubahannya. Kemudian karena struktur kalimat bahasa Indonesia dengan bahasa Jepang sangat berbeda sehingga menyebabkan banyak orang merasa sulit dalam membentuk kalimat bahasa Jepang terutama pelajar asing yang baru belajar bahasa Jepang. Seperti yang kita ketahui bahwa struktur kalimat bahasa Indonesia SPOK sedangkan struktur kalimat bahasa Jepang SOKP. 


\section{REFERENSI}

Alwi, Hasan, dkk. 2003. Tata Bahasa Baku Bahasa Indonesia. Jakarta: Balai Pustaka.

Chaer, Abdul. 2009. Sintaksis Bahasa Indonesia (Pendekatan Proses). Jakarta: PT Rineka Cipta. Fatimah, Siti. 2012. "Analisis Kontrasif Struktur Kalimat Bahasa Arab dan Bahasa Persia. Skripsi. Yogyakarta : Unversitas Islam Negeri Sunan Kalijaga Yogyakarta.

Hidayat, Syarifudin dan Sedarmayanti. 2002. Metodologi Penelitian. Bandung : CV. Mandar Maju.

Indrowaty, Sri Aju. 2014.”Jenis Kesalahan Yang Biasa Terjadi Dalam Karangan Siswa Berbahasa Jepang”. Jurnal Pendidikan. Vol.3. No. 2. Diakses pada 4 februari 2019.

Istiqomah, Novie Lita. 2016. "Struktur Kalimat, Struktur Paragraf, dan pola Pengembangan Paragraf Dalam Wacana Perundang-Undangan Tetang Pendidikan Tahun 2014". Skripsi. Yogyakarta : Universitas Sanata Dharma Yogyakarta.

Mahsun. 2012. Metode Penelitian Bahasa. Jakarta : PT Raja Grafindo Persada.

Mellia, Khasanah Prihatin Maryam. 2015.'Pengaruh Kemampuan Bunpou Terhadap Kemampuan Sakubun Pada Mahasiswa Semester IV Angkatan 2012 Prodi Pendidikan Bahasa Jepang UNNES. Skripsi.Semarang : Universitas Negeri Semarang.

Moleong, Lexi J. 2002. Metode Penelitian kualitatif. Bandung : PT Remaja

. 2014. Metode Penelitian kualitatif. Bandung : PT Remaja RosdaKarya.

Muhammad. 2016. Metode Penelitian Bahasa. Yogyakarta : Ar-ruzz Media.

Nurastuti, Wiji. 2007. Metodologi Penelitian. Magelang : Ardana Media.

Nursan, Dermanda Ridhawaty. 2016. "Kontrruksi Kalimat Dalam Karangan Mahasiswa Transfer Yunnan Minzu University (YMU) Di Universitas Negeri Yogyakarta. Skripsi. Yogyakarta : Universitas Negeri Yogyakarta.

Onafiani, Libriana. 2015. "Analisis kontrasif Struktur Kalimat Pasif Bahasa Jepang Dengan Kalimat Pasif Bhasa Jawa". Skripsi. Malang : Universitas Brawijaya.

Ramlan, M. 2001. Ilmu Bahasa Indonesia Sintaksis. Yogyakarta: CV Karyono.

Setiyadi, Ag. Bambang. 2006. Metode Penelitian untuk Bahasa Asing. Yogyakarta: Graha Ilmu.

Sudaryanto. 1988. Metode Linguistik ke Arah Memahami Metode Linguistik. Yogyakarta : Gajahmada University Press. 
Sudjianto. 2010. Metode Keterampilan Pembelajaran Bahasa Jepang. Bekasi : Kesaint Blanc.

Sudjianto, dan Ahmad Dahidi.2009. Pengantar Linguistik Bahasa Jepang. Bekasi : Kesaint Blanc.

Sugiyono. 2014. Metode Penelitian Kuantitatif Kualitatif dan R\&D. Bandung : Alfabeta.

Sutedi, Dedi. 2003. Dasar-Dasar Linguistik Bahasa Jepang. Bandung : Humaniora.

Sutedi, Dedi. 2009. Penelitian Pendidikan Bahasa Jepang. Bandung: Humaniora.

Sutedi, Dedi. 2009. "Beberapa Alternatif untuk Mengatasi Masalah dalam Pembelajaran Sakubun". Jurnal Pendidikan Bahasa Jepang ASPBJI Korwil Jabar. Vol.2. No.2. FBSS UPI. Diakses pada 24 September 2018.

Tarigan, Henry Guntur. 1990. Pengajaran Tata Bahasa. Bandung : Angkasa. Zaim, M. 2014. Metode Penelitian Bahasa. Padang: FBS UNP Press.

Zalman, Hendri. 2012. "Penggunaan Teknik 5W $+1 \mathrm{H}$ di dalam Pembelajaran Menulis Sakubun”. Seminar dan Workshop Pengajaran Bahasa Jepang ASPBJI. FIB UNAND 